\title{
The automatic recording of aggression in pigeons: A comparison of two methods with live targets
}

\author{
PHILIP G. MULLER and CARL D. CHENEY \\ Utah State University, Logan, Utah 84322
}

\begin{abstract}
Three pigeons were exposed to a fixed-time response independent food-delivery schedule and a live target pigeon restrained in a holder mounted on a spring and microswitch assembly. This common method of recording aggression was compared with a photocell system, and both were evaluated by observation of video-tape recordings. Dependent variables included the number of interfood intervals with an attack, attacks per minute, and attack duration. The photocell proved more reliable than the microswitch and correlated highly with observations of both the number of interfood intervals with an attack for three subjects and attack duration for two. Neither apparatus provided accurate information about the rate of at tacks. The microswitch apparatus was not sensitive to changes in the subject's attack topography, while both recording devices were susceptible to activation by responses in the attacking pigeon other than discrete pecks or physical blows. In view of these findings, attacks per minute may not be an appropriate measure of aggression in studies using such devices.
\end{abstract}

When food-deprived pigeons are exposed to an intermittent food-delivery schedule, they will sometimes attack an available target (Azrin, Hutchinson, \& Hake. 1960; Dove, Rashotte. \& Katz, 1974; Flory. 1969). Frequently, a device similar to that used by Azrin et al. (1966) is employed to record aggression (Chereck. Thompson. \& Heistad, 1973; Flory, 1969; Knutson, 1970; Richards \& Rilling. 1972), wherein either a live or a taxidermically prepared pigeon is strapped into a restrainer mounted on a microswitch and spring assembly. When sufficient force is applied to some part of the target (Flory, 1969) or holder (Knutson. 1970), the microswitch contacts close; this defines the occurrence of an attack. Aggression is recorded as attacks per minute. Precautions are usually taken to insure that attacks can be directed toward the target from only one angle and that the subjects normal ambulatory movements within the experimental chamber do not cause accidental microswitch closures (e.g. Knutson, 1970).

Our experience and analysis of video tape recordings of attacking pigeons in an experimental setting and with a recording device similar to that of Azrin et al. (1966) revealed several problems. For example, attack topography varies considerably both within and between subjects. An attack episode may consist of the subject's taking the target's neck or head feathers in its beak and vigorously shaking the target from side to side. This often results in multiple microswitch

This research was supported in part by a gift from the AIR Foundation. The authors thank Shan Juvelin for her valuable assistance and Deborah Muller for drawing the tigures. Reprints may be obtained from either author. Department of Psychology. Utah State University, Logan, Utah 84322. closures, when in fact only a few pecks were directed at the target. At the other extreme, a subject may peck around the eyes of the target with short, highly localized jabbing movements. These are sometimes directed horizontally and fail to displace the microswitch assembly, which is designed to activate primarily on downward forces. We also observed, as did Azrin et al. (1966). that microswitch closures occur as a result of strong defensive movements by the target. This usually happens (1) just before an attack as a result of a "threat" by the subject, (2) during an attack. or (3) immediately after the food magazine crele and independent of an approach by the subject. Furthermore, the microswitch assembly is not designed to measure attack duration. Adjustments must be made in order to estimate the length of an attack episode. For example, a timer may be set to operate from the first microswitch closure until $1 \mathrm{sec}$ clapses without a switch closure (Webbe, DeWeese, \& Malagodi. 1974).

The reliability of our spring-switch system, based on designs from the literature, varied considerably with subject attack topography and the defensive movements of the target. Direct observation or video recording and observer scoring are time-consuming alternatives. This report presents one solution to some of these problems and provides data comparing two methods of recording attack behavior in pigeons.

\section{METHOD}

\footnotetext{
Subjects

Three White King pigeons. maintained at $80+( \pm 15 \mathrm{~g})$ of freefeeding weights, were used. The subjects had had limited prior experience with an autoshaping procedure (Brown \& Jenkins, 1908). in which a brietly illuminated key light signaled the opportunity to attack. Approximately $10 \%$ of the trials contained a
} 


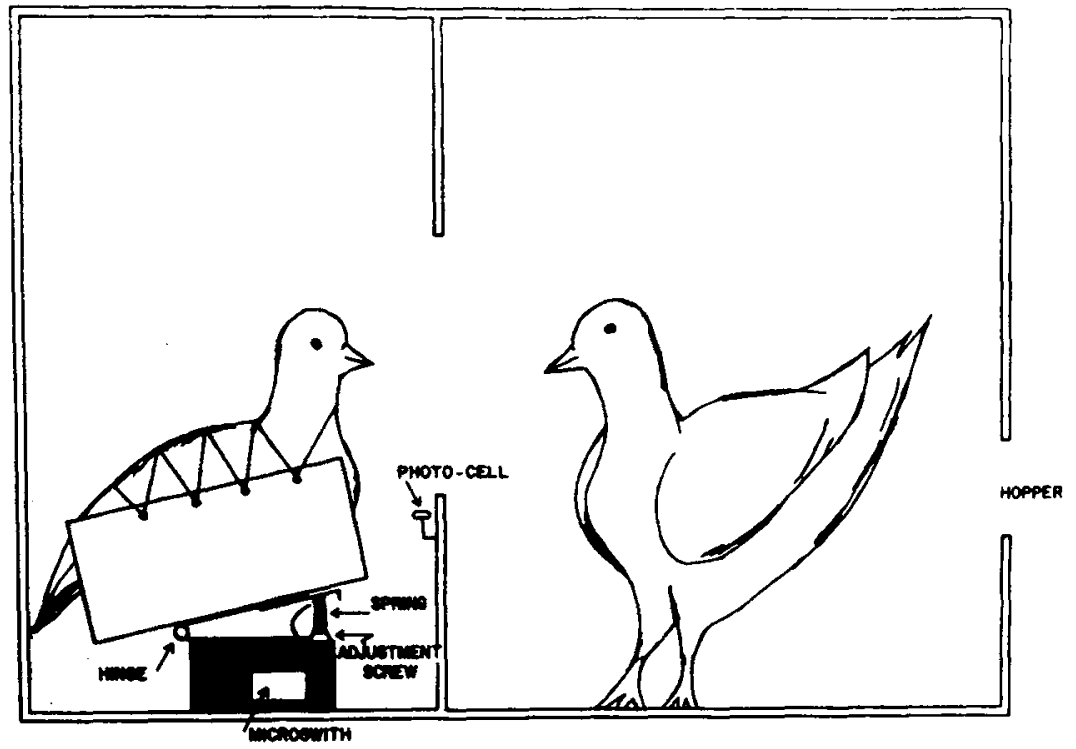

Figure 1. Schematic of two methods of recording attack in pigeons. The entire chamber was $60.9 \mathrm{~cm}$ square. Horizontal distance between target restrainer and photocell could be adjusted.

keypeck and $75 \%$ of the trials an attack. Two additional nondeprived White King pigeons were assigned to each subject as target birds; they were alternated every other day to allow for recovery from injury received during attacks.

\section{Apparatus}

The experimental chamber, $60.9 \mathrm{~cm}$ high $\times 35.5 \mathrm{~cm}$ wide $x$ $10.9 \mathrm{~cm}$ deep, was enclosed in a fan-ventilated, sound-attenuating shell. The hopper wall, ceiling, and two walls were of burnished aluminum; one wall was clear Plexiglas. A food magazine opening was centered in one wall $10.1 \mathrm{~cm}$ above the tloor. The target bird was placed behind a $15.2 \times 15.2 \mathrm{~cm}$ opening (with the lower edge $12.7 \mathrm{~cm}$ above the tloor) in the wall opposite the food magazine. a 20 . W houselight in the center of the ceiling provided constant illumination.

The target bird was restrained in a Li-shaped plastic restrainer mounted on a spring-and-nicroswitch assembly patterned after Azrin et al. (1966). A daily adjustment was made for each individual target such that a dowmard force of $100 \mathrm{~g}(0.98 \mathrm{~N})$ against the target's head activated the microswitch. The target bird could move only its head and neck. and when positioned, its head was approximately $5.0 \mathrm{~cm}$ behind, and directly in the center of. the tarect wall opening (see Figure 1 ).

The photocell was located $1.2 \mathrm{~cm}$ below and in the center of the lawer edge of the target wall opening. The target bird could not operate the photocell. A $7.5-W$ light mounted $15 \mathrm{~cm}$ above the target wall opening provided additional illumination in the target bird's compartment. The sensing device consisted of a photoelectric cell (Radio-Shack No. 276-67?) connected to one input of a locally designed and constructed operational amplitier (Figure 2). The other amplitier in put was used as the reference and adjusted once each day. The circuit was a voltage comparator, and was operational over a wide brightness range.

Events were programmed by conventional relay circuitry and attacks were recorded on impulse counters and a tour-pen event recorder. Both microswitch and photocell outputs were pulse-formed to obtain attack totals. Activities within the chamber were recorded with a Sony AV -3600 ) video tape camera and recorder. The camera. with 1:18 lens. was mounted on a tripod 3 it in front of the chamber.

\section{Procedure}

The subjects were immediately exposed to a fixed-time 2-min response-independent food-delivery schedule with the target in place. Microswitch and phorocell detisitions of attack were whained for every session. Only the photocell recorded attack duration. Video tape fron each session was randomly assigned to one of three observers for scoring. The observers were instructed to press and release a push button for each separate peck at the target. Each buttonpress accunulated on an impulse counter and a running time meter. When the observer could not differentiate discrete pecks cither hecaluse of rapid head mosements or because the pigeon was engaged in behatrior that coukl not cleats be chassilicd is latrget pecking. such as pulling and jerking head or neck feathers. the observer kept the butem depressed. For all exeept the last hice sessions. the obsetwer merely determined the number of intertend intervals containing an attack. During the last fine semims. total allatcks per session and total attack durations were alow detined and seored by the observer

sessunis began with a 2-min intersal and terminated after 30 hopper presentations. catch consisting of 3-sec access to Purina piecun (hom. Sessions were conducted at approsimately the same rimk eath das. das per wech.

\section{RESULTS AND DISCUSSION}

Photocell records of interfood intervals with an attack and attack duration were fairly consistent with those of observers (Figure 3). For any one session. there was never more than a $10 \%$ difference in reporting the percent of interfood intervals with an attack.

Microswitch definitions of the percent of interfood intervals with an attack were typically inaccurate and

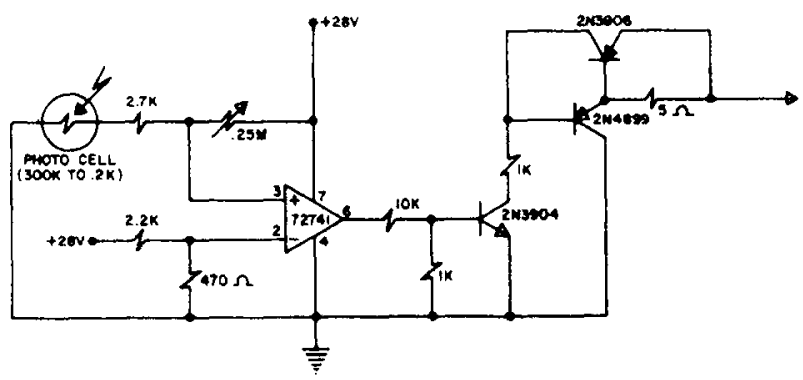

Figure 2. Diagram of the photocell operational amplifier. 
varied considerably both within and between subjects. For Subjects Pl and P3, there were few er microswitch reports than observer reports, and the microswitch did not reliably follow changes in the direction of atlacks (e.g.. P1. Sessions 6 through 8). For P2, the microsuitch was more sensitive than it was for $P 1$ and P.3 in terms of the percent of interfood intervals with an altack. However, the ypical error in the first nine sessions was due to the struggling movements of the target. For example, during Session 3, no attacks were reported by the observer or photocell, but $33 \%$ of the intertood intervals contained an attack according to the microswitch. This error was not as prevalem for $P 1$ and $P 3$. since their targets were less active.

In wrder to index the reliability of the photocell and microswitch. correlation coefficients were calculated between the observer and microswitch data and the observer and photocell data. Analysis of variance (Table 1) showed that for the photocell, there was no significant difference in recording the number of interfood intervals with an attack and total attack duration. Photocell definitions of the number of interfood intervals with an attack correlated nicely "ith the observer's for all three pigeons. With data obtained from the microswitch, this was true only for P2.

However. high correlations could occur independently of agreement with the locus of attacks in the interfood interval as defined by the observer. Thus, the event recorder tapes containing the photocell. microswitch, and observer definitions of attack were analyzed (sec Figure 4). The intertood intervals of the last five sessions for each bird were divided into eight 15 -see bins. The apparatus was considered accurate for each bin in which it agreed with the observers. The photocell and microswitch agrement with the observer for $\mathrm{P} 1$ was $98.6 \%$ vs. $51.7 \%$. $94.4 \%$ vs. $89.7 \%$ for $\mathrm{P} 2$, and $99.4 \%$ vs. $27.9 \%$ for P3. This analysis suggests that the signiticant correlations in Table 1 for the number of interfood intervals with an attack did not necessarily occur due to accidental apparatus closures in which there was also an observer-defined attack.

The photocell also correlated signiticantly with observations of attatck duration for P2 and P3, and the
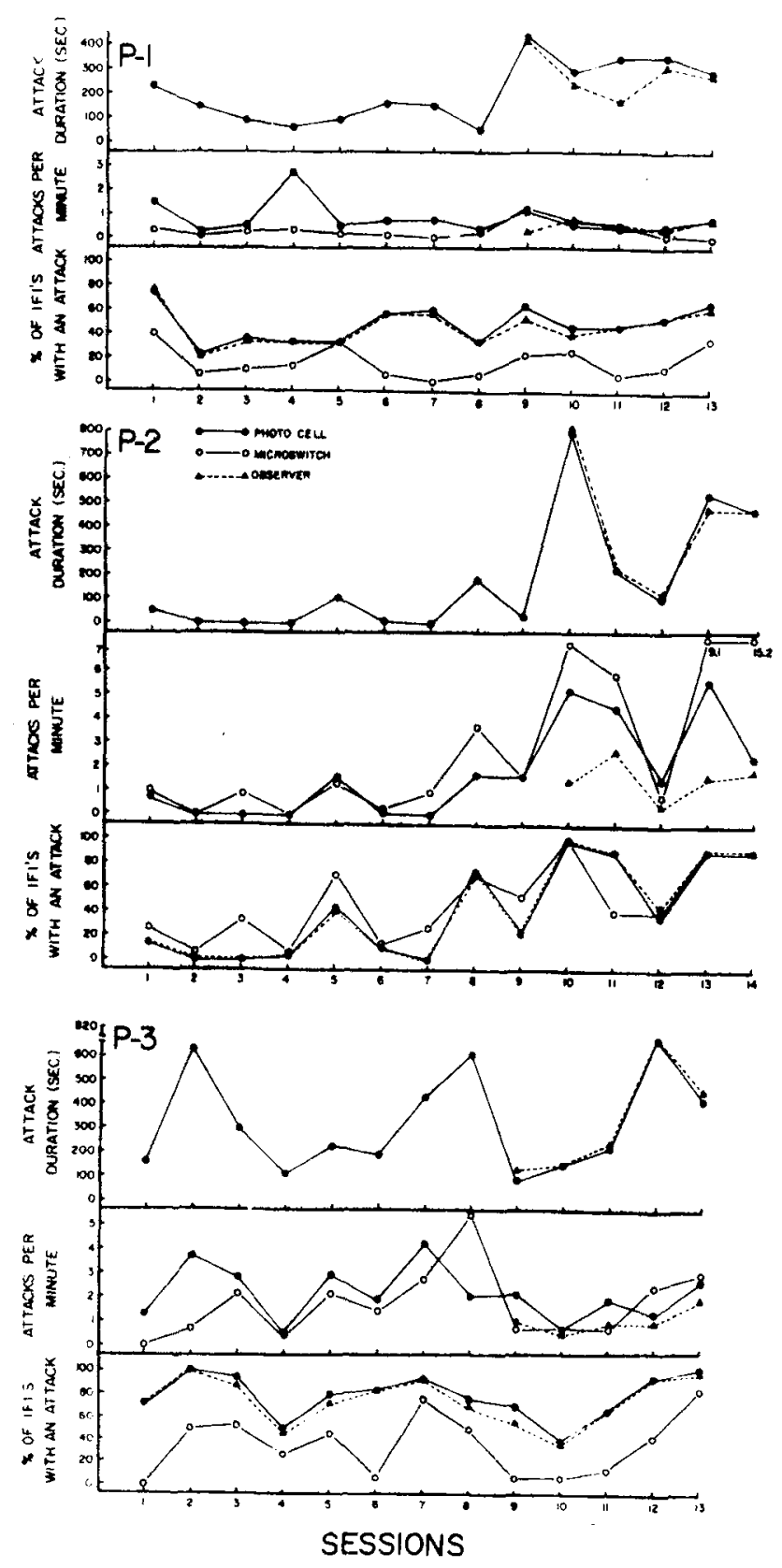

Figure 3. Percent of interfood intervals with an attack, attacks per minute, and attack duration as a function of sessions for each subject, obtained from the photocell, microswitch, and observer.

Table 1

Correlation Coefficients and Comparison of Means Between the Observer and Photocell and the Observer and Microswitch

\begin{tabular}{|c|c|c|c|c|c|c|c|}
\hline \multirow{2}{*}{$\frac{\text { Subject }}{\text { Pl }}$} & \multirow{2}{*}{$\begin{array}{l}\text { Comparison } \\
\text { OBS-PHOTO } \\
\text { OBS-MICRO }\end{array}$} & \multicolumn{2}{|c|}{$\begin{array}{l}\text { Number of IFIs } \\
\text { With an Attack }\end{array}$} & \multicolumn{2}{|c|}{ Attacks Per Minute } & \multicolumn{2}{|c|}{ Attack Duration } \\
\hline & & $N=13$ & $\begin{array}{l}.97^{*} \\
.20 \dagger\end{array}$ & $N=5$ & $\begin{array}{l}-.35 \\
-.64\end{array}$ & $N=5$ & .70 \\
\hline $\mathrm{P} 2$ & $\begin{array}{l}\text { OBS-PHOTO } \\
\text { OBS-MICRO }\end{array}$ & $N=14$ & $\begin{array}{l}.99 * \\
.93^{*}\end{array}$ & $N=5$ & $\begin{array}{l}.43 \\
.48 t\end{array}$ & $N=5$ & $.98^{*}$ \\
\hline P3 & $\begin{array}{l}\text { OBS-PHOTO } \\
\text { OBS-MICRO }\end{array}$ & $N=13$ & $\begin{array}{l}.97^{*} \\
.65^{*} \dagger\end{array}$ & $N=5$ & $\begin{array}{l}.84^{*} \\
.29\end{array}$ & $N=5$ & $.99 *$ \\
\hline
\end{tabular}




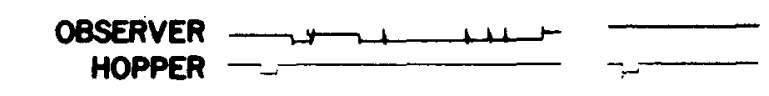

MCROSWITCH
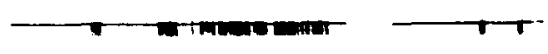

PHOTO-CELL

A

Figure 4. Event recorder tape containing examples of the types of errors characteristic of the two recording systems. Example A: microswitch and photocell outputs not contiguous with reports by the observer. Example B: microswitch closure in the absence of an attack.

attack rate for P3. Attack rate proved to be the most unreliable dependent measure with either system. since the correlation coefficients were negative (P1), nor statistically significant (P2 and P3). or showed a significant difference between means (P2). Figure 4A illustrates some possible sources of these discrepancies. Frequently, when the microswitch and photocell were activated, multiple outputs were produced, while both microswitch and photocell outputs were not always contiguous with attacks reported by the observer. While part of this error may have been due to the observer's inability to discriminate discrete pecks, the attacks in Figure 4A consisted only in part of pecking the target. The majority of the two episodes consisted of behavior that could not be described clearly as pecking the target, i.e.. pulling and jerking the head and neck feathers. Thus. both apparatuses were susceptible to activation by responses other than discrete pecks. Movements of the target sometimes confounded this problem for the microswitch, during as well as in the absence of attacks, as in Example B of Figure 4.

Although the percent of interfood intervals with an attack for $P 1$ and $P 3$ suggest that the operating force of the microswitch may have been set too high, lowering the force requirement may have resulted in an even greater discrepancy in the rate measure. as occurred for P2. However, we do not believe that the discrepancy in Pl's and P3's data was simply a function of the force requirement per se, but was in fact due to variability in the force requirement necessary to activate the microswitch as a function of the locus of pecks across the frontal area of the target.

In the present study, the photocell proved to be a reliable method of recording aggression for both number of interfood intervals with an attack and attack duration. With the current level of recording device sophistication and the complex and variable nature of the pigeons' attack repertoire, attacks per minute may not be an appropriate measure of aggression, either in terms of the reliability of the measurement or the behavior exhibited by the subject. Indeed, Azrin et al (1966) warned against several of the problems discussed in this paper and did not use attacks per minute as a dependent measure of aggression. We must concur, and urge future researchers in this area to publish reliability data for their apparatus with respect to the dependent measures examined.

\section{REFERENCES}

Azrin, N. H., Hutchinson, R, R., \& Hake, D. F. Fxtinction-induced aggression. Joumal of the Experimental Analysis of Behavior, 1966, 9, 191-204.

Brown, P. L. \& Jenkins. H. M. Autoshaping of the pigeon's key peck. Joumal of the Experimental Analysis of Behavior. $1968,11,1.8$.

Chfreck. D. D. Thompson. T.. \& Heistad, G. T. Responding maintained by the opportunity to attack during an interval tood-reinforcement schedule. Journal of the Experimental Alualysis of Beharior, 1973, 19, 113-123.

Dove. L. D.. Rashotre, M. E.. \& Katz. H. N. Development and maintenance of attack in pigeons during variable-interval reinforcement of key pecking. Journal of the Experimenal Analysis of Behavior, 1974, 21, 463-496.

Flory. R. K. Attack behavior as a function of a minimum interfood interval. Journal of the Experimental Analysis of Buhavior. 1969. 12. 825-828.

Knetson. J. F. Aggression during fixed-ratio and extinction components of a multiple schedule of reinforcement. Journal of the Experimental A nalysis of Beharior, 1970, 13, 221-231.

Richards. R. W. \& Rilling. M. Aversive aspects of a tixedinterval schedule of food reinforcement. Journal of the Experimental Analysis of Behavior, 1972, 17, 405-412.

Webre. F. M., DeWeese, J.. \& Malagodi. E. F. Induced attack during multiple fixed-ratio, variable-ratio schedules of reinforcement. Journal of the Experimental Analysis of Behavior. 1974. 22. 197.206.

(Received for publication November 8, 1974; revision received April 11, 1975.) 